OPEN ACCESS

Edited by:

Bruno Poucet,

Centre National de la Recherche

Scientifique (CNRS), France

Reviewed by:

Charles N. Allen,

Oregon Health and Science University,

United States

Concettina Fenga,

University of Messina, Italy

${ }^{*}$ Correspondence:

Nouria Lakhdar-Ghazal

nlakhdarghazal@gmail.com

Received: 03 June 2017 Accepted: 08 September 2017 Published: 22 September 2017

Citation:

Sabbar M, Dkhissi-Benyahya O, Benazzouz A and Lakhdar-Ghazal N

(2017) Circadian Clock Protein

Content and Daily Rhythm of Locomotor Activity Are Altered after Chronic Exposure to Lead in Rat. Front. Behav. Neurosci. 11:178 doi: 10.3389/fnbeh.2017.00178

\section{Circadian Clock Protein Content and Daily Rhythm of Locomotor Activity Are Altered after Chronic Exposure to Lead in Rat}

\author{
Mariam Sabbar ${ }^{1}$, Ouria Dkhissi-Benyahya ${ }^{2}$, Abdelhamid Benazzouz ${ }^{3,4}$ and \\ Nouria Lakhdar-Ghazal ${ }^{\text {* }}$ \\ 'Équipe de Recherche sur les Rythmes Biologiques, Neurosciences et Environnement, Faculté des Sciences, Université \\ Mohammed V, Rabat, Morocco, ${ }^{2}$ INSERM, Stem Cell and Brain Research Institute U1208, University of Lyon, Université \\ Claude Bernard Lyon 1, Lyon, France, ${ }^{3}$ Institut des Maladies Neurodégénératives, Univ. de Bordeaux, UMR5293, Bordeaux, \\ France, ${ }^{4}$ Centre National de la Recherche Scientifique, Institut des Maladies Neurodégénératives, UMR5293, Bordeaux, \\ France
}

Lead exposure has been reported to produce many clinical features, including parkinsonism. However, its consequences on the circadian rhythms are still unknown. Here we aimed to examine the circadian rhythms of locomotor activity following lead intoxication and investigate the mechanisms by which lead may induce alterations of circadian rhythms in rats. Male Wistar rats were injected with lead or sodium acetate (10 mg/kg/day, i.p.) during 4 weeks. Both groups were tested in the "open field" to quantify the exploratory activity and in the rotarod to evaluate motor coordination. Then, animals were submitted to continuous $24 \mathrm{~h}$ recordings of locomotor activity under 14/10 Light/dark (14/10 LD) cycle and in complete darkness (DD). At the end of experiments, the clock proteins BMAL1, PER1-2, and CRY1-2 were assayed in the suprachiasmatic nucleus (SCN) using immunohistochemistry. We showed that lead significantly reduced the number of crossing in the open field, impaired motor coordination and altered the daily locomotor activity rhythm. When the LD cycle was advanced by $6 \mathrm{~h}$, both groups adjusted their daily locomotor activity to the new LD cycle with high onset variability in lead-intoxicated rats compared to controls. Lead also led to a decrease in the number of immunoreactive cells (ir-) of BMAL1, PER1, and PER2 without affecting the number of ir-CRY1 and ir-CRY2 cells in the SCN. Our data provide strong evidence that lead intoxication disturbs the rhythm of locomotor activity and alters clock proteins expression in the SCN. They contribute to the understanding of the mechanism by which lead induce circadian rhythms disturbances.

Keywords: suprachiasmatic nucleus, lead, locomotor activity, clock proteins, rat, Parkinsonism

\section{INTRODUCTION}

Lead poisoning has been reported to induce Parkinsonism and epidemiological studies suggested that lead plays a synergistic role with other heavy metals in the incidence of Parkinson's disease (PD) (Gorell et al., 1997, 1999a,b). In fact, the role that lead may play to generate Parkinsonism has been strongly supported by many studies demonstrating that this heavy metal 
is affecting the dopaminergic (DA) system as reported in PD (Ehringer and Hornykiewicz, 1960). Jason and Kellogg (1981) reported that neonatal exposure to lead in rats induced an irreversible degeneration of the nigro-striatal dopaminergic system in parallel with behavioral and neurochemical abnormalities (Jason and Kellogg, 1981). Other studies have shown that lead exposure in adolescent rat also decreased dopamine levels (Kala and Jadhav, 1995) and that this decrease may not be related to the loss of tyrosine hydroxylase immunoreactive neurons in the pars compacta of substantia nigra as reported by Tavakoli-Nezhad et al. (2001).

We have recently shown that sub-chronic exposure to lead acetate induced motor deficits in parallel with a decrease in the content of both DA in the striatum and noradrenaline (NA) in the cortex (Unpublished data).

Non-motor deficits, such as anxiety disorder have also been observed in the rat following lead exposure (Sabbar et al., 2012). Similar motor and non-motor disorders have been reported in PD patients (Shulman et al., 2001; Barone et al., 2009; Breen et al., 2014; Alzahrani and Venneri, 2015), in animal models of PD (Delaville et al., 2012; Faggiani et al., 2015) and in animals exposed to manganese (Bouabid et al., 2014). Interestingly, nonmotor symptoms have been shown to precede the manifestation of motor disabilities in PD patients (Chaudhuri et al., 2006; Ishihara and Brayne, 2006). Furthermore, one of the common non-motor disorders reported in PD patients is sleep disorder, including insomnia, excessive daytime sleepiness and disturbed rapid eye movement (REM) sleep behavior (Gunn et al., 2010; Menza et al., 2010; Willison et al., 2013).

The sleep-wake cycle is one of the many daily rhythms regulated by the circadian timing system (Pace-Schott and Hobson, 2002). Circadian rhythms are controlled by the master clock localized in the suprachiasmatic nuclei (SCN) of the anterior hypothalamus in mammals (Stephan and Zucker, 1972). The circadian clock generates molecular circadian rhythms through cell-autonomous autoregulatory transcriptional/translational feedback loops consisting of the bHLH/PAS transcription factors BMAL1 and CLOCK, which heterodimerize and drive transcription of many genes, including their own negative feedback repressors, such as Period (Per1, Per2, Per3), Cryptochrome (Cry1, Cry2) and Reverb genes, which repress BMAL1/CLOCK-mediated transcription (Reppert and Weaver, 2001; Lowrey and Takahashi, 2004; Okamura, 2004).

The consequences of lead exposure on the circadian system have been investigated by few studies who showed that lead exposure affected the locomotor activity rhythm in rats (Collins et al., 1984). Using the rat model of lead-induced Parkinsonism, the present study aimed to investigate whether lead exposure affects both the circadian rhythms of locomotor activity and the molecular machinery of the SCN. The effects of a subchronic low-level lead treatment on motor behavior and coordination was first evaluated; then, we monitored the daily and circadian locomotor activity rhythm and quantified clock proteins expression; BMAL1, PER1, PER2, CRY1, and CRY2 in the SCN.

\section{MATERIALS AND METHODS}

\section{Animal Housing}

Male Wistar rats (Central animal service, Mohammed V University, Faculty of Sciences, Rabat, Morocco) weighing 70-80 g were used for behavioral and immunohistochemical studies. Rats were kept individually in polycarbonate cages, in a thermostatically controlled room (temperature: $24^{\circ} \mathrm{C}$, relative humidity: $45 \%)$ under a $14 \mathrm{~h} / 10 \mathrm{~h}$ light/dark cycle (14/10 LD; lights on at $06: 00 \mathrm{~h}$ ) for 3 weeks, with access to food and water ad libitum. Body weights were monitored throughout the experiment. All experiments were performed in accordance with the European Communities Council Directive 2010/63/UE. Approval was granted by the Ethic Committee of Veterinarians of Hassan II Institute of Agronomy and Veterinary Medicine of Rabat, Morocco, and all efforts were made to minimize the number of animals used and their suffering.

\section{Lead Administration}

Animals were randomly divided into two groups: leadintoxicated $(n=26)$ and control $(n=20)$ rats. In our experiments, lead-intoxicated rats received daily i.p. injections of lead acetate free-pyrogen solution $(10 \mathrm{mg} / \mathrm{kg}$; Sigma, France) at zeitgeber time 4 (ZT4, $4 \mathrm{~h}$ after light on), for 30 days. Control rats received sodium acetate (10 $\mathrm{mg} / \mathrm{kg}$; Sigma, France) solution in the same conditions.

\section{Behavioral Assessments}

\section{Assessment of Spontaneous Locomotor Activity}

Exploratory behavior was evaluated in the open field test as previously described by Rodrigues et al. (1996) with modification. The apparatus is a wooden box $(75 \mathrm{~cm}$ long, $45 \mathrm{~cm}$ wide and $35 \mathrm{~cm}$ high), the surface was divided into 15 similar squares of $15 \mathrm{~cm}$ each side. Prior to lead or sodium acetate administration, all rats were habituated to the open field for 3 days. At the first and the last day of the i.p. injections of lead or sodium acetate, rats were tested once in a quiet and dimly lit for $5 \mathrm{~min}$ session. Exploratory behavior was evaluated by counting the number of crossing (transition from one square to another) and rearing (animal stands on its two legs).

\section{Assessment of Motor Coordination}

Motor coordination was evaluated using the rotarod test. The apparatus is equipped with a rotating bar which rotates at different and adjustable speeds. Rats were placed on the rotating bar with a fixed speed of 20 rotations per minute (rpm). The performance on the rotarod was measured once a day at ZT4 $(10: 00 \mathrm{~h})$ for 4 consecutive days, and the time was recorded until the rat failed to stay on the bar.

\section{Assessment of Locomotor Activity Rhythm}

Locomotor activity was continuously monitored using infrared motion captors placed over the cages and a computerized data acquisition system CAMS (Circadian Activity Monitoring System, INSERM, France) as previously described (El Moussaouiti et al., 2010), and analyzed using Clocklab software (Actimetrics, Evanston, Illinois, USA). Different parameters were analyzed: the period and the amplitude using Chi-squared 
periodogram, daytime and nighttime activities, onset and offset variabilities, activity onset and offset which correspond to the average clock (or circadian) time of activity onset or activity offset respectively. The diurnality index [mean activity during the light phase/(mean activity during the light phase + mean activity during the dark phase)] as previously described (Refinetti, 2006). Animals with indices above 0.5 are more active during the day than during the night. Alpha $(\alpha)$ was also analyzed and is defined as the duration of the active period of the animal. To assess the entrainment of the rhythm of locomotor activity by light, animals were subjected to $6 \mathrm{~h}$ phase advance of the $14 / 10$ LD cycle (lights on at 00:00 h; LD AT) for 3 weeks after the last injection of either lead or sodium acetate. The phase angle and the number of days necessary to entrain to the new 14/10 LD cycle were determined for each rat. The phase angle was defined as the difference between the onset activity and the time of lights-off. In our study, the rhythm of locomotor activity is considered entrained to the new LD cycle when the onset of activity presents a stable phase relationship relative to the time of light off $( \pm 0.3 \mathrm{~h})$ for at least 10 days as previously described (Lahouaoui et al., 2014).

Recording of the circadian locomotor activity was pursued in constant darkness (DD) for 15 days, and the free-running periods (Tau, $\tau$ ) were calculated using Clocklab (Actimetrics, Evanston, Illinois, USA). Then, rats were exposed to $14 / 10$ LD cycle (lights on at $06: 00 \mathrm{~h}$ ) for 10 days.

\section{Experimental Procedures}

Experiment 1: Prior to lead or sodium acetate administration, all rats were maintained under $14 / 10 \mathrm{~h}$ LD cycle, with lights on at $06: 00 \mathrm{~h}$ and were habituated to the open field for 3 days. On dayl (Figure 1A), rats were assigned randomly to receive an i.p. injections of one of the following substances: lead acetate (10 $\mathrm{mg} / \mathrm{kg} ; n=6)$, and sodium acetate $(10 \mathrm{mg} / \mathrm{kg} ; n=6)$ at ZT 4 $(10: 00 \mathrm{~h})$ for 30 days. On day 30, after the last injection of lead or sodium acetate, a rat was placed into the open field box and allowed to explore the box for about $5 \mathrm{~min}$. Exploratory behavior was evaluated by counting the number of crossing (transition from one square to another) and rearing (animal stands on its two legs).

Twenty-four hours after the open field test, the performance on the rotarod was evaluated in the same rats. Rats were placed on the rotating bar with a fixed speed of $20 \mathrm{rpm}$. The performance on the rotarod was measured once a day at ZT4 for 4 consecutive days, and the time was recorded until the rat failed to stay on the bar (Figure 1A).

Experiment 2: Rats were maintained under 14/10 h LD cycle, with lights on at 06:00 and daily locomotor activity rhythms of rats were recorded for 22 days, prior lead or sodium acetate treatment (LD; Figure 1B). On day 1, rats were assigned randomly to receive an i.p. injection of one of the following substances: lead acetate ( $10 \mathrm{mg} / \mathrm{kg} ; n=6)$, sodium acetate $(10$ $\mathrm{mg} / \mathrm{kg} ; n=6)$ at ZT $4(10: 00 \mathrm{am})$ for 30 days and were maintained under 14/10 h LD cycle (LD+T; Figure 1B). On day 30, after the last injection of lead or sodium acetate, rats were subjected to $6 \mathrm{~h}$ phase advance of the 14/10 LD cycle (lights on at 00:00 h; LD AT) to examine the ability of animals to re-entrain to a new $\mathrm{LD}$ cycle for 22 days (Figure 1B). Rats underwent under total darkness (DD; Figure 1) to assess the circadian locomotor activity rhythm for 14 days followed by 10 days in 14/10 LD cycle (light on at 06:00 h).

\section{Immunohistochemistry}

At the end of the locomotor activity recording period, rats were deeply anesthetized by an injection of sodium pentobarbital (100 mg/kg, i.p.) and perfused with $0.9 \%$ saline followed by $4 \%$ paraformaldehyde (PFA, $300 \mathrm{ml}$ ) in $0.1 \mathrm{M}$ phosphate buffer $(\mathrm{PB}$, $\mathrm{pH}$ 7.4). Brains were removed and post-fixed in $4 \% \mathrm{PFA}$ at $4^{\circ} \mathrm{C}$ for an additional $24 \mathrm{~h}$, rinsed in PBS, and cryo-protected in 30\% sucrose in $0.1 \mathrm{M}$ PBS (phosphate-buffered saline, $\mathrm{pH} 7.4$ ) for additional $24 \mathrm{~h}$ at $4^{\circ} \mathrm{C}$. Collected brains from control $(n=12)$ and lead-intoxicated $(n=12)$ rats were cut into $20 \mu \mathrm{m}$ coronal sections and two series of three alternated sections were collected. We used one of the series for the primary antibodies; anti-PER1, anti-PER2 and anti-BMAL1, and the second serie for the primary antibodies; anti-CRY1 and anti-CRY2.

SCN sections were pre-incubated in $0.1 \mathrm{M}$ PBS, 5\% normal goat serum with $0.4 \%$ Triton $\mathrm{X}-100$ and $1 \%$ bovine albumin serum for $1 \mathrm{~h}$ and then transferred to $2 \%$ normal goat serum containing primary antibody for $48 \mathrm{~h}$ at $4^{\circ} \mathrm{C}(1: 5,000)$. After washes in $0.1 \mathrm{M}$ PBS $(3 \times 10 \mathrm{~min})$, sections were incubated during $2 \mathrm{~h}$ in $0.1 \mathrm{M}$ PBS containing $2 \%$ normal goat serum and biotinylated rabbit anti-goat IgG (1:2,000, Vector laboratories) for $2 \mathrm{~h}$ at room temperature. Sections were then washed in PBS $(3 \times 10 \mathrm{~min})$, and incubated with the avidin/biotin complex (1:1,000; ABC, Vectastain kit, Vector Laboratories) for $1 \mathrm{~h}$ at room temperature. After several washings (two in $0.1 \mathrm{M} P B S$ and one in $0.05 \mathrm{M}$ Tris buffer (TB, pH 7.6), immunoreactivity was visualized with $0.025 \% \mathrm{DAB}$ (Sigma, France), 0.5\% ammonium nickel sulfate (Sigma, France), in $0.1 \mathrm{M}$ TB containing $0.03 \%$ hydrogen peroxide (Sigma, France), for 6-10 min. Sections were finally washed three times in $0.1 \mathrm{M} \mathrm{TB}$ and once in $0.1 \mathrm{M} \mathrm{PB}$. After processing, tissue sections were mounted onto gelatincoated slides, dehydrated in graded ethanol, cleared in xylene and coverslipped with Eukitt (Sigma, France).

\section{Data Analysis}

All Statistical analyses (behavioral or immunohistochemical analyses) were done using GraphPad Prism program version 6.05 (California, USA). Data are shown as mean \pm SEM and statistical significance was considered for $P<0.05$.

Two-way ANOVA followed by post-hoc Bonferroni were used to compare body weight, number of crossing and rearing, response latency on the rotarod (failure time) between the two groups. Period, tau, activity onset and offset variabilities, $\alpha$, phase angle, and diurnality index were compared using Mann-Whitney test between controls and lead-intoxicated rats. Mean activity counts during the light and the dark phases and the total activity were also analyzed using Mann-Whitney test.

Labeled cell nuclei by PER 1-2, CRY1-2, and BMAL1 were counted manually in 4-5 sections per animal for each primary antibody) of the SCN using a computerized image system (Image J software, imagej.nih.gov/ij/) attached to a light microscope 
A

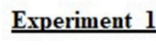

Experimental Design

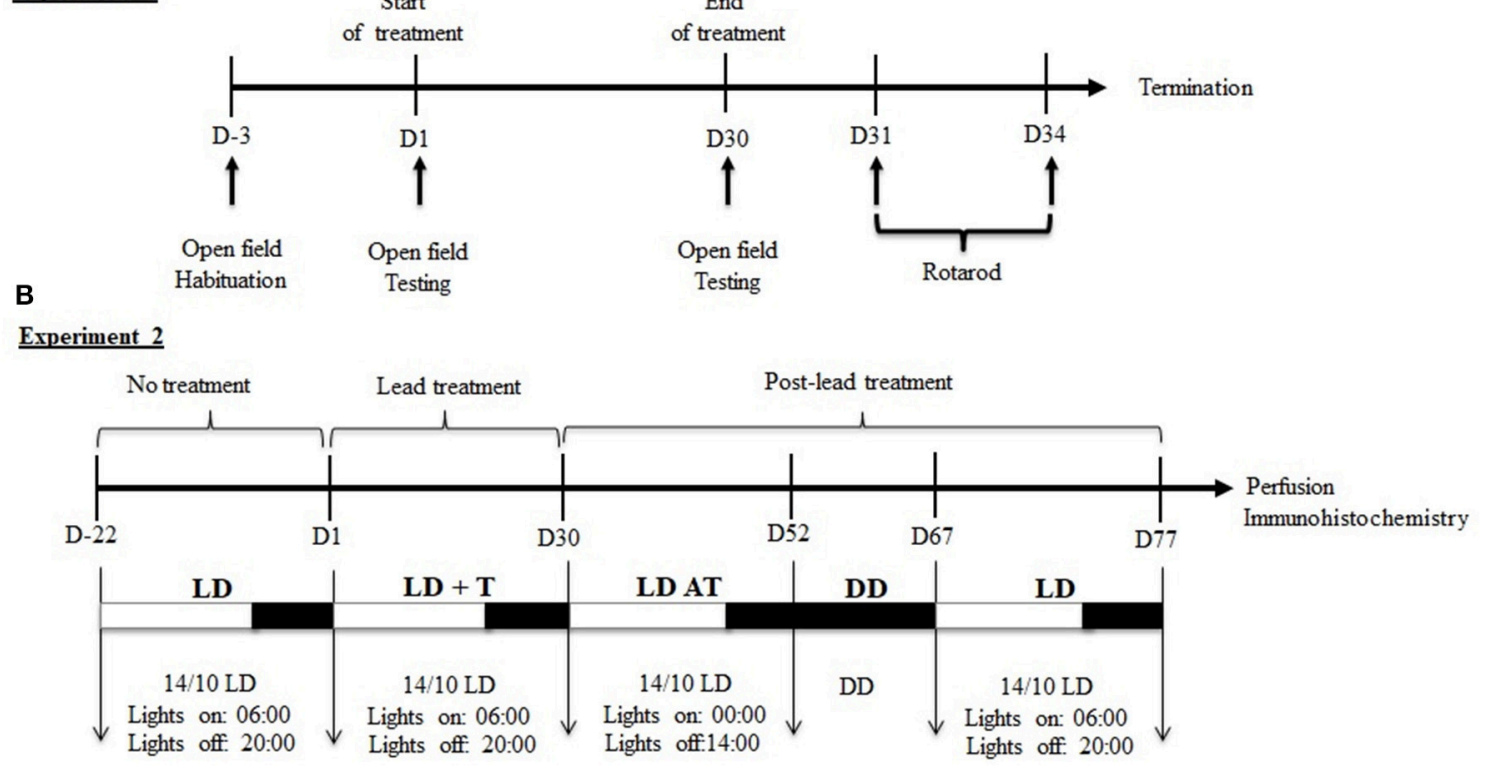

FIGURE 1 | Experimental design of experiments 1 and 2. (A) Experiment1: Sequence of behavioral tests. (B) Experiment2: Sequence of lighting protocols and the duration of each cycle. Under LD cycle, locomotor activity was recording before (LD, 3 weeks), during (LD+T, 4 weeks) and after lead treatment (LDAT, 3 weeks). Locomotor activity was recorded in total darkness (DD) for 15 days.

(Leica Microsystems, Germany). The number of immunoreactive cells (ir-cells) in the SCN was counted in each section and averaged among these coronal sections. Statistical analysis was determined using the Mann-Whitney test.

\section{RESULTS}

\section{Lead Intoxication Decreased Body Weight Gain}

Figure 2 shows the mean body weight ( \pm SEM) of leadintoxicated rats and their respective controls. Two-way repeated measures ANOVA showed significant effects of lead on time $\left[F_{(14,168)}=294.6, P<0.0001\right]$, treatment $\left[F_{(1,12)}=5.672\right.$, $P<0.05]$ and interaction (treatment $\times$ time) $\left[F_{(14,168)}=13.57\right.$, $P<0.0001]$. At the beginning of the experiment, all animals had similar body weights (lead-intoxicated rats: $69.75 \pm 3.22$ vs. control rats: $71.33 \pm 2.39$ ). From day 19 to day 29 of injections, post-hoc test revealed that body weight of lead-intoxicated rats became significantly reduced compared to controls and resulted in $23 \%$ loss of body weight gain on day 29 (Bonferroni post-hoc test, $P<0.001$; Figure 2).

\section{Lead Intoxication Induced Hypoactivity Measured in the Open Field Test}

In the open field test, we expected that exploratory activity will be higher independently to the treatment in day 30 , because the age of the rat influences the exploration rate; infant or adolescent rats had less exploratory activity than adults (Smith and Morrell,

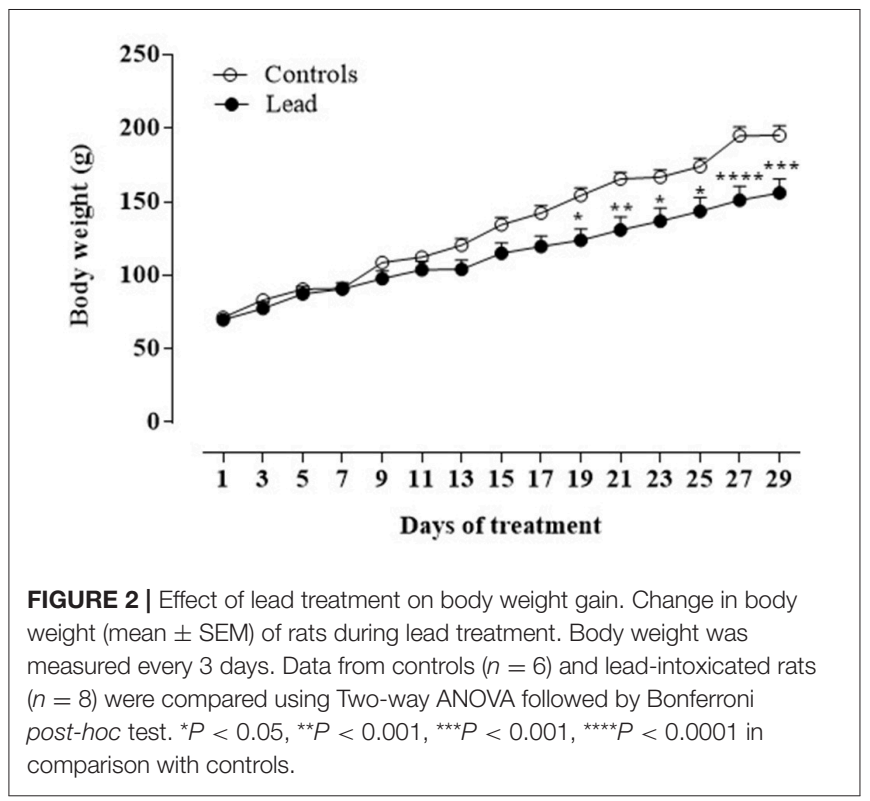

2007). We focused, then in our data analysis in the effect of lead intoxication on the exploratory activity on day 30 compared to their controls on the same test day.

Figure 3 shows the spontaneous locomotor activity (crossing; Figures $\mathbf{3 A}, \mathbf{B}$ ) as measured in the open field test. There were no statistically significant differences among the groups in the number of crossing and rearing movements (Figures 3A,B) on 

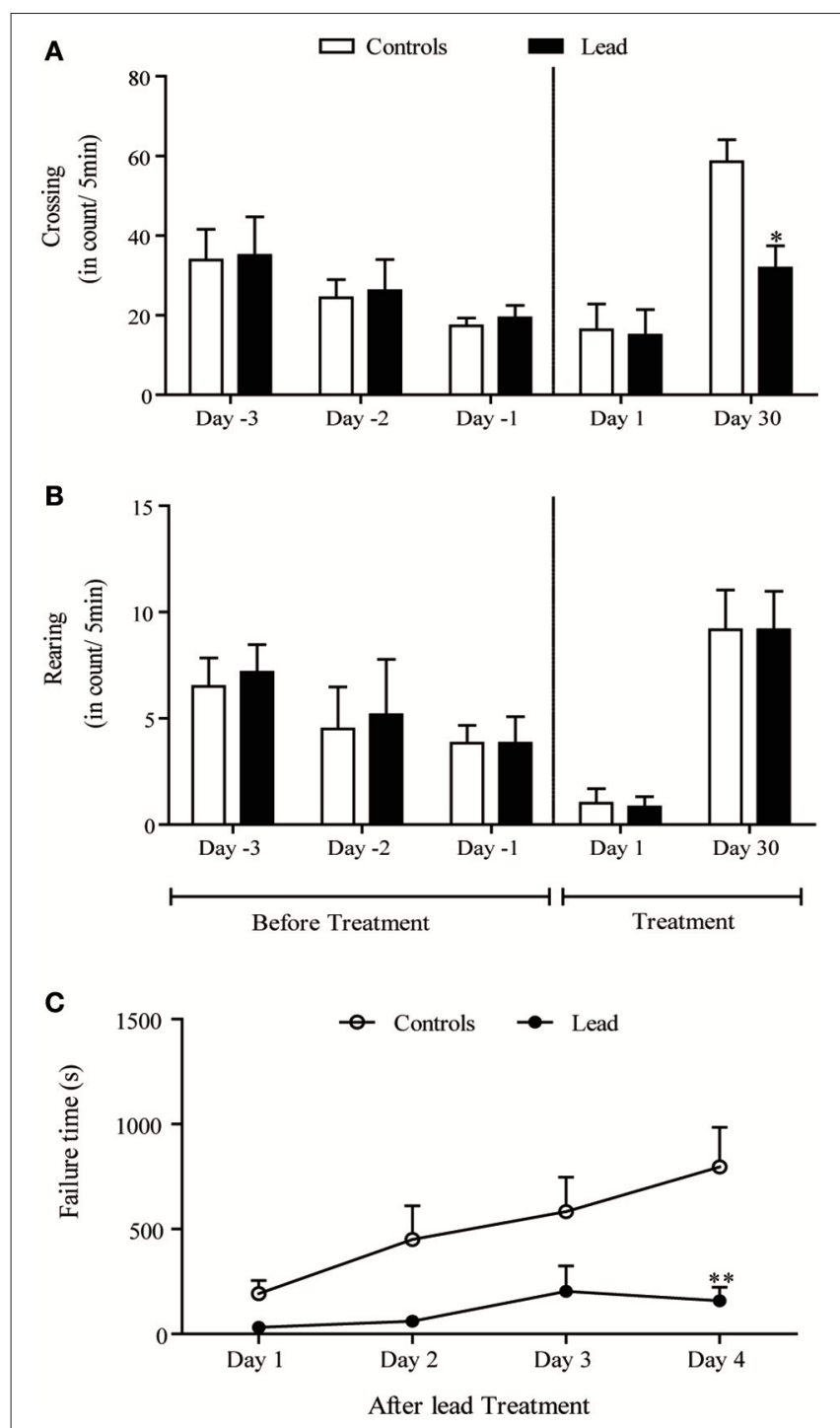

FIGURE 3 | Lead treatment reduced locomotor activity and disturbed motor coordination Histograms of exploratory activity represent the number of crossing (A) and rearing (B) measured in the open field test during 5 min sessions on the first day and the last day of lead acetate treatment. Motor coordination performance histogram represent the time that rat stayed on the rotating bar using the rotarod test at the end of lead treatment (C). Values are the mean \pm SEM. Data from controls $(n=6)$ and lead-intoxicated rats $(n=6)$ were compared using two-way ANOVA followed by a post-hoc Bonferroni. ${ }^{\star} P<0.05,{ }^{\star \star} P<0.01$ in comparison with controls.

the habituation period before injections, as well as on the first day of injections.

Upon a re-introduction into the open field on day 30, the pattern of the exploratory activity in rats was notably different; the number of crossings significantly decreased in lead-intoxicated rats compared to controls $\left[-45.59 \%, F_{(4,40)}=\right.$ 3.20, $P<0.05$, two-way ANOVA followed by Bonferroni posthoc test; Figure 3A]. However, the number of rearings did not significantly change $\left[F_{(4,40)}=0.040, P>0.05\right.$, two-way ANOVA, Figure 3B].

\section{Lead Intoxication Impaired Motor Coordination Evaluated in the Rotarod Test}

The motor coordination was assessed using the rotarod test. Latency time in seconds was recorded. Two-way repeated measures ANOVA of motor coordination after lead acetate or sodium acetate injections showed a significant effects on time $\left[F_{(3,30)}=9.400, P=0.0002\right]$, and treatment $\left[F_{(1,10)}=6.932, P=\right.$ $0.0250]$ but not on treatment $\times$ time interaction $\left[F_{(3,30)}=2.802\right.$, $P=0.0568]$. Lead-intoxicated rats did not significantly increase their latency time on the rotating bar, in contrast to controls, in which the latency time on the rotating bar increased significantly (Bonferroni post-hoc test, $P<0.01$, Figure 3C).

\section{Lead Intoxication Disturbed the Daily and the Circadian Locomotor Activity Rhythm}

As mentioned earlier (see section Material and Methods), all rats were randomly divided into two groups; controls and leadintoxicated rats. The daily locomotor activity rhythm of all rats was monitored when animals were exposed to $14 / 10 \mathrm{LD}$ cycle prior to any treatment. Each animal served as its own control. Representative actograms before treatment (LD), and during lead or sodium acetate injections $(\mathrm{LD}+\mathrm{T})$ are shown in Figure 4.

In $\mathrm{LD}$, during the pre-treatment, all rats showed a strong daily profile of locomotor activity with the main activity was recorded during the dark phase. The average daytime activity counts was $447.1 \pm 29.34$ and the average nighttime activity counts was $1,390 \pm 94.28$. After this pre-treatment rats, we divided randomly all rats to two groups lead-intoxicated and control group and the data were re-analyzed and no significant differences were observed in the mean activity.

The activity profile for representative control and leadintoxicated rats are shown in Figure 5A. During lead intoxication $(\mathrm{LD}+\mathrm{T})$, daytime activity counts were significantly increased in lead-intoxicated rats when compared to their controls $(666.8 \pm$ 43.14 vs. $430.6 \pm 61.68$ in controls $P<0.01$, Mann Whitney test, Figure 5B). However, no significant differences were found between lead-intoxicated rats and controls in the nighttime activity counts $(1,236 \pm 83.03$ vs. $1,506 \pm 376.5$ in controls, Figure $5 C)$ or in the total activity counts $(1,903 \pm 100.5$ vs. $1,937 \pm 399.2$ in control rats, Figure 5D). The diurnality index was significantly higher in lead-intoxicated rats $(0.35 \pm 0.02)$ compared to controls $(0.25 \pm 0.03)(P<0.01$, Mann Whitney test; Figure 5E).

Periodogram analysis showed that both groups remained entrained to the 14/10 LD cycle during lead intoxication (LD+T), with similar period $(23.96 \pm 0.009 \mathrm{~h}$ in controls vs. $23.98 \pm$ $0.006 \mathrm{~h}$ in lead-intoxicated rats; Figure 5F) but with a delay in their activity onset. The nighttime activity began in leadintoxicated rats before light OFF (onset variability was $0.94 \pm$ $0.22 \mathrm{~h}$ in controls vs. $1.67 \pm 0.34 \mathrm{~h}$ in lead-intoxicated rats; $P$ $<0.05$, Mann Whitney test; Figure 5G). No difference in the offset of activities was observed (offset variability was $0.49 \pm$ $0.13 \mathrm{~h}$ in controls vs. $0.88 \pm 0.16 \mathrm{~h}$ in lead-intoxicated rats; $P=$ 0.054, Mann Whitney test, Figure 5H). $\alpha$ significantly decreased in lead-intoxicated rats with a mean value of $13.01 \pm 0.16 \mathrm{~h}$ 

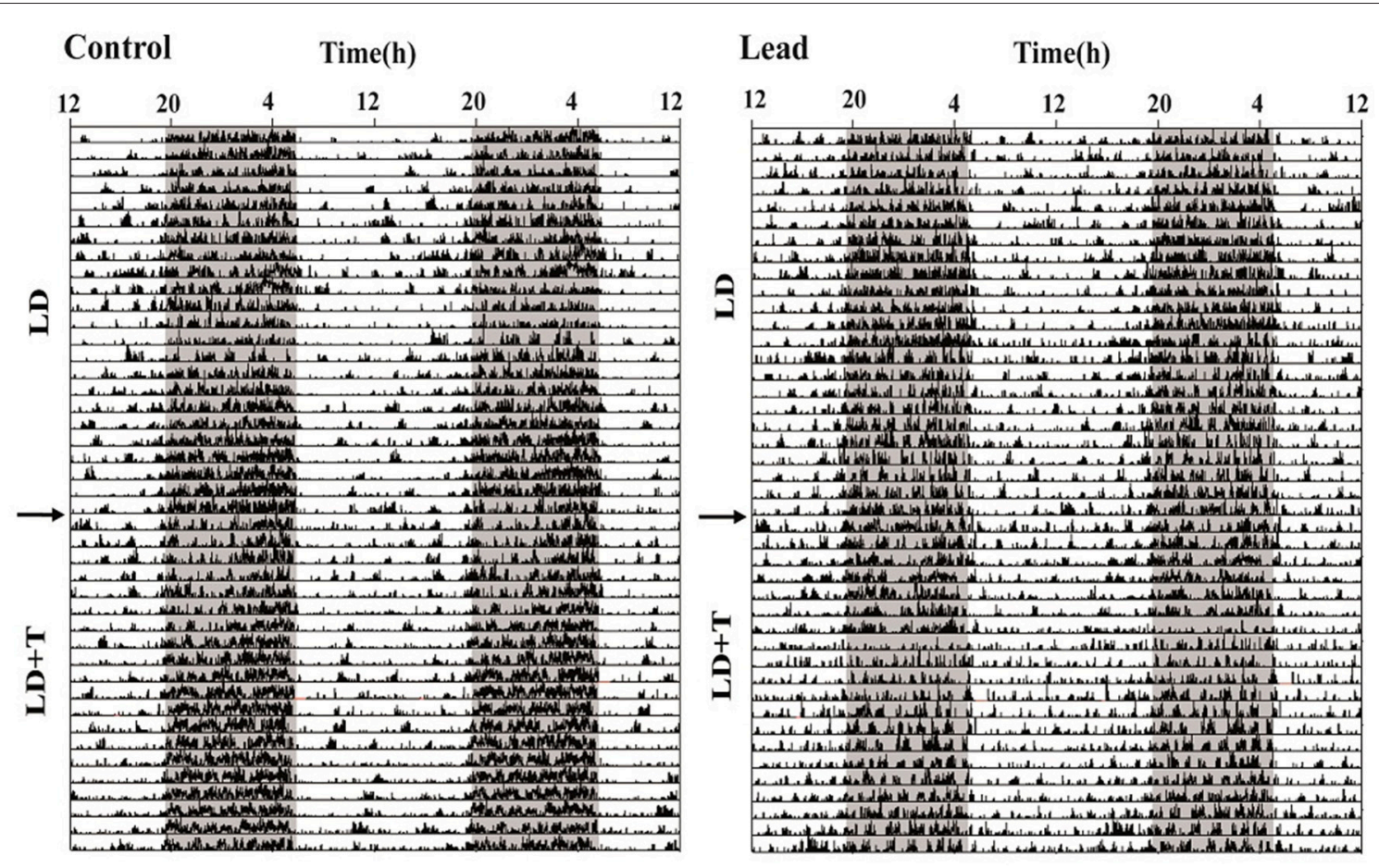

FIGURE 4 | Representative double-plotted actograms illustrating locomotor activity rhythm of a control rat and lead-intoxicated rat. The horizontal axis represents clock time (h), with $48 \mathrm{~h}$ of data shown on each row, while the vertical axis represents study days. The gray bar represents the dark phase and white bar represent the light phase. The arrow indicates the beginning of lead or sodium acetate treatment.

by comparison to controls $(13.71 \pm 0.08 \mathrm{~h} ; \mathrm{P}=0.0034$, Mann Whitney test, Figure 5I).

One day after the last injection of lead or sodium acetate, rats have been exposed to a $6 \mathrm{~h}$ phase advance of the 14/10 LD cycle to examine their ability to entrain to a new LD cycle.

Representative actograms from control and lead-intoxicated rats are shown in Figure 6A. Control and lead-intoxicated rats were able to synchronize their locomotor activity rhythm to the new LD cycle. In controls, entrainment was achieved after $8.67 \pm$ 1.17 days, whereas in lead-intoxicated rats, the entrainment was attained after $8.85 \pm 1.81$ days. No significant difference between the two groups was observed (Mann Whitney test, $P=0.80$, Figure 6B).

Three weeks after cessation of lead and sodium acetate injections (LD AT; light on at 00:00), rats showed a strong daily profile of the locomotor activity with a similar period $(23.96 \pm 0.009$ in controls vs. $23.98 \pm 0.001$ in lead-intoxicated rats; Figure 7A) but a number of parameters were altered. The variability of activity offset was significantly higher in leadintoxicated rats $(0.66 \pm 0.103 \mathrm{~h}$ vs. $0.41 \pm 0.047 \mathrm{~h}$ in control rats; $P<0.05$, Mann Whitney test; Figure 7B), whereas, no difference was observed between the two groups for the variability of activity onset $(0.89 \pm 0.15 \mathrm{~h}$ in lead-intoxicated rats vs. $0.72 \pm 0.09 \mathrm{~h}$ in control rats; $P>0.05$, Mann Whitney test, Figure 7B).

A significant decrease in the mean nighttime activity was observed in lead-intoxicated rat $(1,425 \pm 110.3$ vs. $2,282 \pm$ 294.8 in control rats; Figure 7C, $P<0.05)$. No difference was observed in daytime activity (501.1 \pm 99.11 in controls vs. 503.1 \pm 64.62 in lead-intoxicated rats; Figure 7C). The total activity counts were $2,783 \pm 380.7$ and $1,928 \pm 164.4$ in control and lead-intoxicated rats, respectively (Figure 7C) and the diurnality index was significantly increased in lead-intoxicated rats $(0.26 \pm$ $0.02)$ compared with control rats $(0.17 \pm 0.02)$ (Figure $7 D$, Mann Whitney test, $P<0.01)$.

Figure 7E shows the daily change in activity during the light and dark phase under the new LD cycle of rats 3 weeks after lead treatment and the analysis of the daily activity levels (mean activity counts) showed that lead profoundly induced hypoactivity during the dark phase (Two-way repeated measures ANOVA showed a significant effect of treatment $[P<0.0001$, $\left.F_{(3,489)}=509.6\right]$, whereas neither the time nor the interaction (time $\mathrm{x}$ treatment) were significant $(P>0.05)$.

In order to examine the impact of lead on the circadian clock, we subjected rats to constant conditions of darkness (DD) for 15 days. Under these conditions, lead-intoxicated rats exhibited a locomotor circadian rhythm with a similar free-running period $(\tau)$ when compared to controls $(23.95 \pm 0.038 \mathrm{~h}$ in controls vs. $23.93 \pm 0.087 \mathrm{~h}$ in lead-intoxicated rats; $P=0.72$, Mann Whitney test; Figure 8A). The activity onsets variability was significantly higher in lead-intoxicated rats $(1.15 \pm 0.143 \mathrm{~h}$ vs. $0.69 \pm 0.09 \mathrm{~h}$ in controls, Mann Whitney test, $P<0.05$; Figure 8B) whereas the activity offsets variability was not significantly altered by lead intoxication $(0.91 \pm 0.148 \mathrm{~h}$ vs. $0.45 \pm 0.09 \mathrm{~h}$ in controls, Mann Whitney test, $P=0.084$, Figure $8 B$ ). Likewise, no differences 


\section{$\mathbf{L D}+\mathbf{T}$}

A

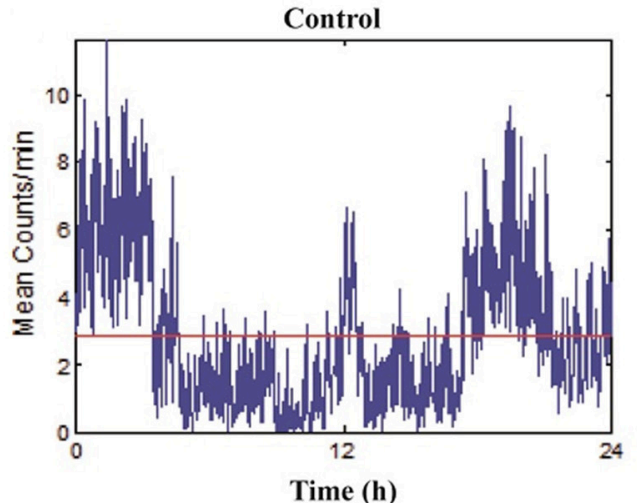

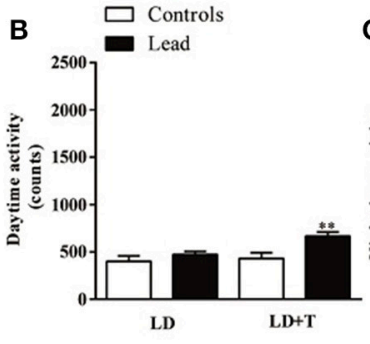

$\mathbf{F}$



C

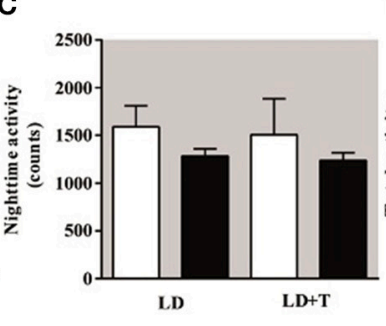

$A^{\prime}$

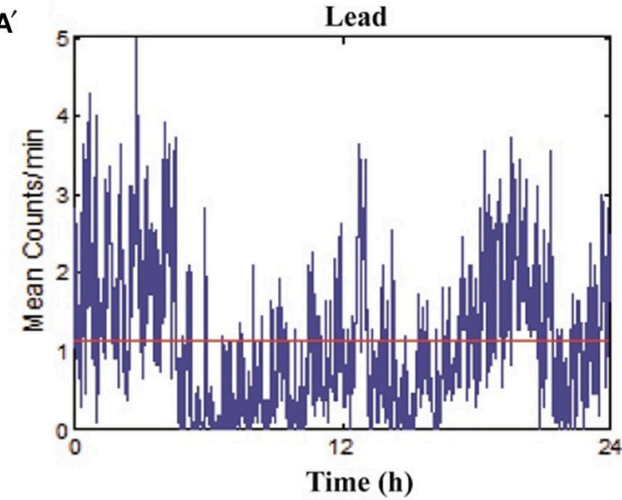

D
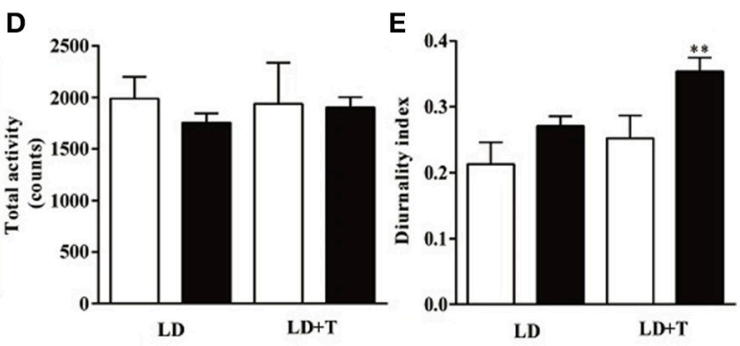

I
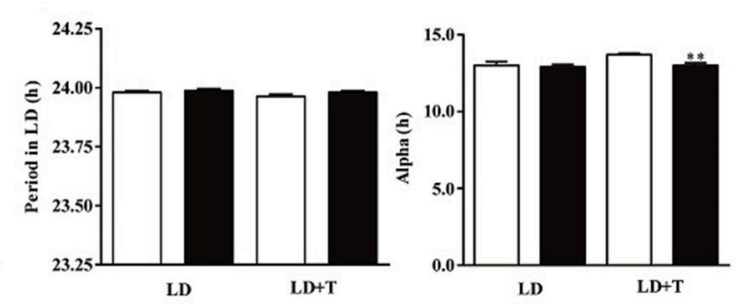

FIGURE 5 | Circadian parameters for controls and lead-intoxicated rats in LD before (LD) and during lead or sodium acetate treatment (LD+T). (A) Activity profile illustrates the $24 \mathrm{~h}$ activity in LD cycle in lead-intoxicated rat compared to control rat. (B) Daytime activity counts, (C) Nighttime activity counts, (D) Total activity counts, (E) Diurnality index, (F) Period (G) Onset variability, (H) Offset variability, and (I) Alpha. Data from controls $(n=7)$ and lead-intoxicated rats $(n=13)$ were compared using Mann-Whitney test. ${ }^{\star} P<0.05,{ }^{\star \star} P<0.01$ in comparison with controls.

were found in the activity during the subjective day, in the activity during the subjective night or the total activity (Figure 8C).

\section{Effect of Lead Intoxication on the Clock Proteins Immunoreactivity in the SCN}

Figures 9-11 show the mean number ( \pm SEM) of clock protein immunoreactivity (ir-) in the SCN of lead-intoxicated rats and their respective controls. Lead induced a significant decrease in the mean number of -BMAL1, -PER1, and -PER2 ir-cells in the SCN. In control rats, the average of ir-BMAL1 cells is $374 \pm 25.9$, whereas, in lead-intoxicated rats, the average of ir-BMAL1 cells is $303.2 \pm 19.7$ (Mann-Whitney test, $P<0.05$; Figure 9).

The mean number of ir-PER1 cells is $416 \pm 22.72$ in controls, whereas, in lead-intoxicated rats, the mean number of ir-PER1 cells is $302.1 \pm 35.93$ (Mann-Whitney test, $P<0.05$; Figure 10), and the mean number of ir-PER2 cells is $409.7 \pm 19.40$ in controls, whereas, in lead-intoxicated rats, the mean number of ir-PER2 cells is $277.7 \pm 25.91$ (Mann-Whitney test, $P<0.05$; Figure 10).

In contrast, lead did not affect CRY1 and CRY2 immunoreactivity in the SCN (Figure 11). The number of ir-CRY1 cells is $227 \pm 45.3$ and $311.1 \pm 24.5$ in lead-intoxicated and control rats. For CRY2, the number of ir-CRY2 cells is $296 \pm$ 22.7 in controls and $227 \pm 28.5$ in lead-intoxicated rats.

\section{DISCUSSION}

The main interesting result obtained in this study is the alteration in the locomotor activity rhythm induced by lead toxicity which parallels with a decrease in clock protein expression. Interestingly, these alterations are obtained in all groups of rats that express neurobehavioral dysfunction. 


\section{A}

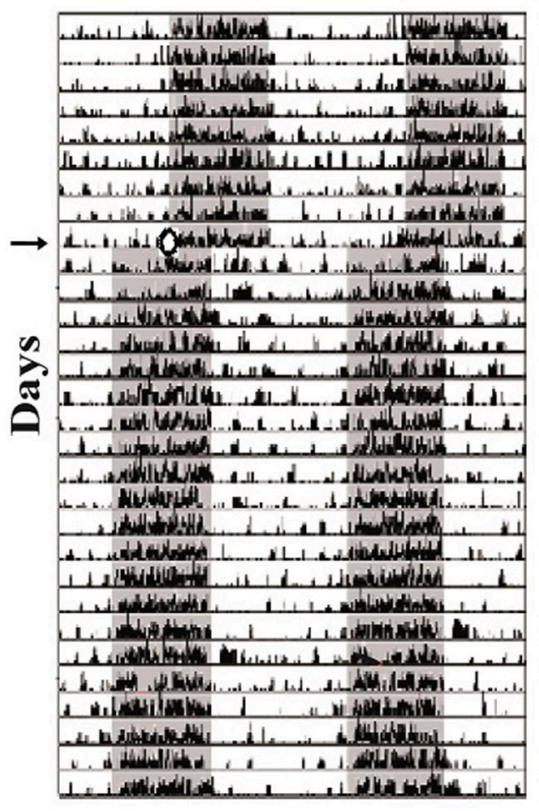

B

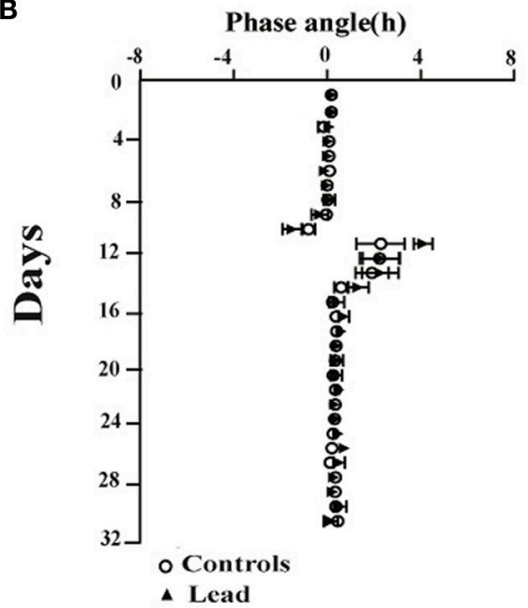

Lead 1

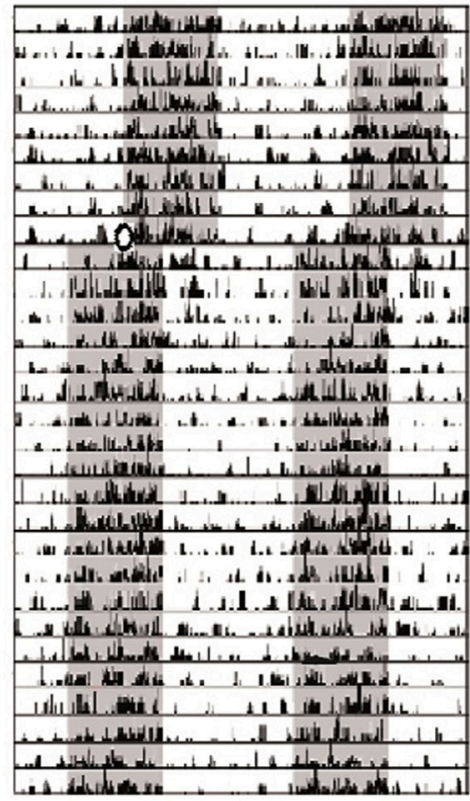

Lead 2

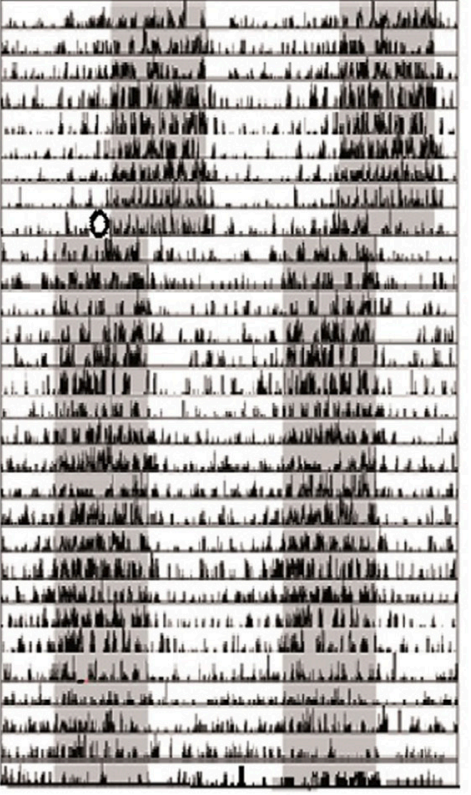

Phase angle(h)

$-8$

\begin{abstract}
$-4$
\end{abstract}



Controls
Phase angle(h)

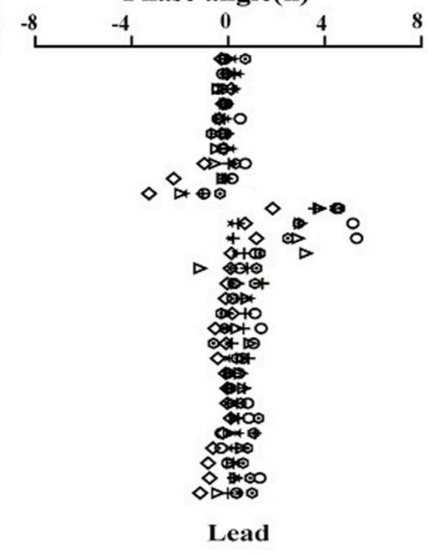

FIGURE 6 | Lead treatment did not affect photic entrainment. (A) Three double-plotted actograms of locomotor activity for control and two lead-intoxicated rats under $L D$ cycle $(L D+T$. $\longrightarrow L D$ AT). The horizontal axis represents time (h), with $48 \mathrm{~h}$ of data shown on each row, while the vertical axis represents study day. The gray bar represents the dark phase and white bars represent the light phase. (B) Phase angles of activity onsets showing the low onset precision after the entrainment to the new LD (LDAT) cycle for all rats (Mean \pm SEM) and individual data from controls and lead-intoxicated rats.

In the current study, we have confirmed in Wistar rat (experiment 1) that lead induces progressive decline in body weight gain, decreased the exploratory activity (number of crossing in open field; Figure 3A) and impaired motor coordination (Figure 3C) as early shown by our previous findings in Sprague dawley rat (Sabbar et al., 2012) and other works (Reiter et al., 1975; Overmann, 1977; Gill et al., 2003; NourEddine et al., 2005; Sansar et al., 2011). Strangely, it seems that in lead-intoxicated rats, the number of rearing in the open filed was not significantly different compared to controls (Figure 3B). However, based on previous data (Shafiqur-Rehman et al., 1991), it is more likely that rearing response has decreased the first days following lead intoxication and then increased on day 30. In addition to motor symptoms (Reiter et al., 1975; NourEddine et al., 2005), non-motor symptoms like the rest/activity rhythm is also affected by lead (Collins et al., 1984). In the present study, we have shown for the first time that lead intoxication impaired the locomotor activity rhythm together with a decrease in BMAL1, PER1, and PER2 content in the SCN without inducing any changes in CRY1 and CRY2 content. These results provide strong evidence that lead disturbs circadian function by probably affecting clock protein expression in the SCN. 


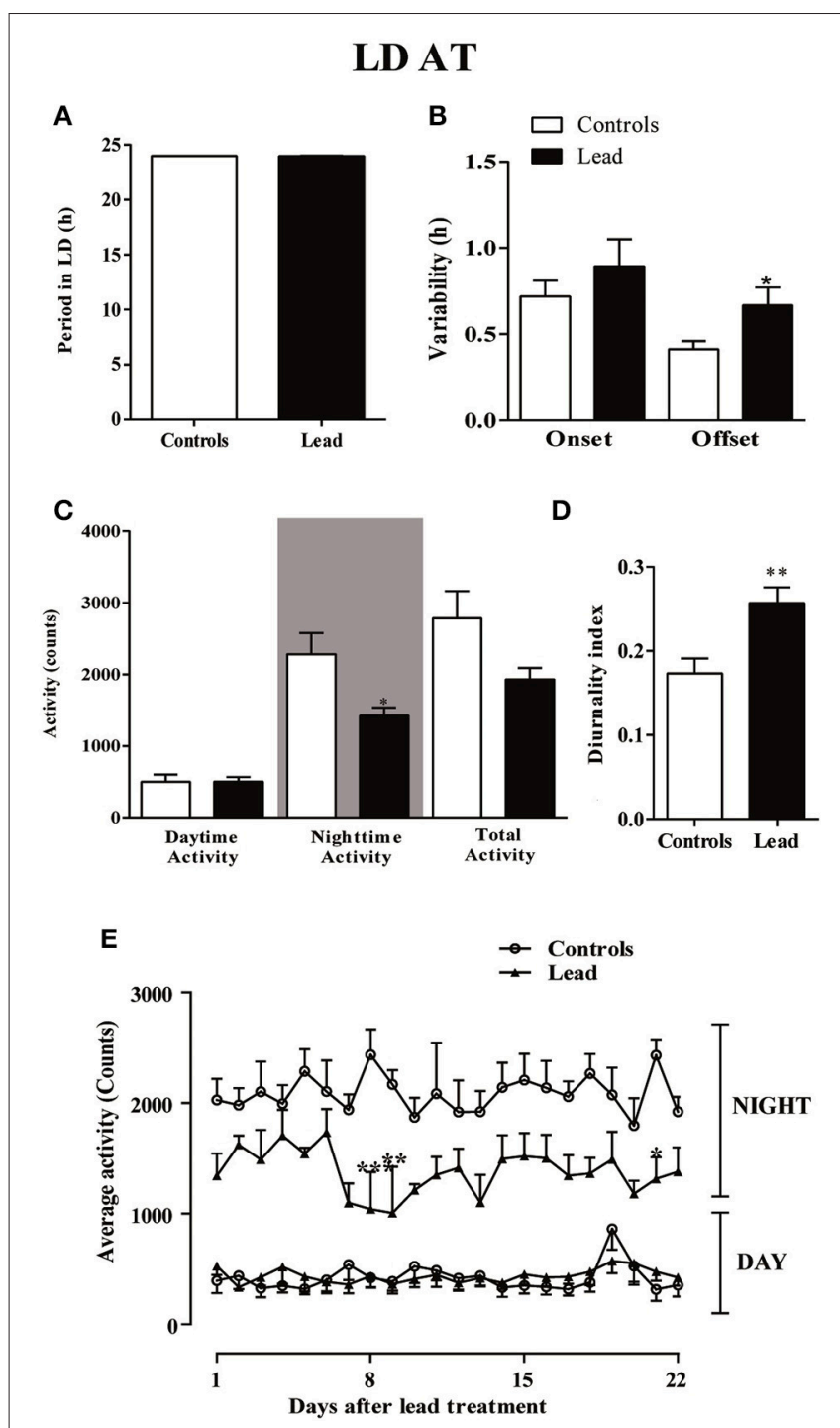

FIGURE 7 | Circadian parameters for controls and lead-intoxicated rats in LD after lead treatment (LDAT). (A) Period, (B) Onset and offset variability, (C) daytime, nighttime and total activity counts, and (D) diurnality index. Data from controls $(n=7)$ and lead-intoxicated rats $(n=7)$ were compared using Mann-Whitney test. ${ }^{\star} P<0.05,{ }^{\star \star} P<0.01$ in comparison with controls. (E) The daily average activity counts from controls $(n=7)$ and lead-intoxicated rats $(n=7)$ were compared using one-way ANOVA followed by Tukey's post-hoc test. ${ }^{\star} P<0.05$, ${ }^{\star \star} P<0.01$, ${ }^{\star \star \star} P<0.001$ in comparison with controls.

In the present work, we show that in lead-intoxicated rats, the $24 \mathrm{~h}$ rest/activity cycle is fragmented under a $14 / 10 \mathrm{LD}$ cycle with activity predominantly expressed during the dark phase (Figure 4). Animals showed impaired locomotor activity rhythm consisting of abnormal phasing to the LD cycle, and strong change in the diurnality index (Figure 5E) than those observed in controls. Moreover, lead-intoxicated rats showed also less precision in their daily locomotor activity rhythm as reflected in the increased activity onsets variability (Figure 5F). No difference was however observed in the period of the $24 \mathrm{~h}$ locomotor activity rhythm. When the LD cycle was advanced by $6 \mathrm{~h}$, both groups adjusted their daily locomotor activity to the new LD cycle; however, the offset variability was higher in lead-intoxicated rats than controls (Figure 7B). Our results enhance earlier observations reported by Collins et al. (1984) and Shafiq ur Rehman et al. (1986). Collins et al. (1984) showed that in pups chronically exposed to lead for many weeks, the circadian spontaneous locomotor activity was significantly affected, whereas Shafiq ur Rehman et al. (1986) reported that lead intoxication affects circadian rhythm of ambulatory activity. In addition, another study has also demonstrated that lead intoxication affects the circadian patterns of the complex stereotyped behaviors (such as rearing, preening, scratching and biting/licking) (Shafiq ur Rehman, 1999). These alterations disturb the ability of the animal to cope and interact with its environment.

Although no definitive causal links between lead intoxication and PD have been proven, there are a considerable number of epidemiological studies suggested that occupational exposure to specific metals including lead may be a high-risk factor for PD (Gorell et al., 1997; Coon et al., 2006; Weisskopf et al., 2010), we then compared $24 \mathrm{~h}$ locomotor activity alterations in lead-intoxicated rats to those observed in $\mathrm{PD}$ patients and animal models of PD and reported in the literature. Interestingly, actograms analysis revealed a significant increase in the mean daytime activity during lead intoxication followed by a decrease in the nighttime activity in lead-intoxicated rats, reflecting a poor consolidation of locomotor activity as previously reported (Collins et al., 1984). These findings reproduced those previously reported in PD patients (van Hilten et al., 1994) and in animal models of PD (Ben and Bruguerolle, 2000; Almirall et al., 2001; Boulamery et al., 2010). They strengthen the hypothesis that lead-intoxicated rats lack the ability to maintain robust locomotor activity rhythm under LD cycle, which is similar to the impairment observed in the circadian rhythms of PD patients. In fact, many studies have demonstrated that lower amplitude rest/activity rhythm affected sleep quality (Langmesser et al., 2009; Smith et al., 2009). Indeed, PD patients expressed a number of circadian rhythm alterations such as insomnia and excessive daytime sleepiness (van Hilten et al., 1994; Stevens et al., 2004; Thorpy and Adler, 2005; Ferreira et al., 2006) and nighttime sleep fragmentation (van Hilten et al., 1993; Gunn et al., 2010) strengthening the hypothesis that the alteration in circadian rhythm parameters in lead-intoxicated rats could explain partially sleep/wake cycle disturbances that occur in PD patients (Arnulf et al., 2002). Several parameters in the sleepwake pattern of animal models of PD have also been described (Fifel et al., 2016). For example, MPTP injection induced a dramatic disruption of sleep/wake architecture associated with reduced (REM) sleep and excessive daytime sleepiness in non-human primate (Barraud et al., 2009). Another study reported a drastic decrease in the latency to the onset of slow wave sleep (SWS) with REM sleep ablation in MPTPtreated rats (Lima et al., 2007). Despite lack of investigations on lead-induced sleep disturbances in human or animals, we found only one report (Kumar and Desiraju, 1992) where the authors showed that lead induced a significant reduction in the delta, theta, alpha and beta band electroencephalogram 



FIGURE 8 | Circadian parameters for controls and lead-intoxicated rats in total darkness (DD) after lead treatment. (A) Tau, (B) Onset and offset variability and (C) subjective activity counts. Data from controls $(n=7)$ and lead-intoxicated rats $(n=7)$ were compared using Mann-Whitney test. ${ }^{\star} P<0.05$ in comparison with controls.

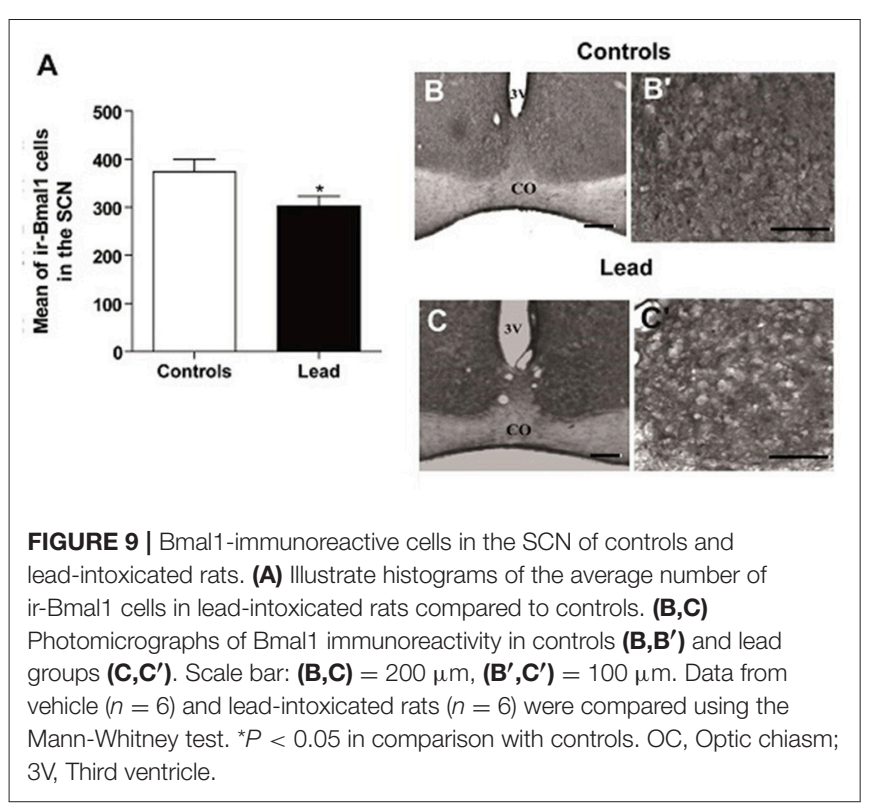

spectral power in both wakeful and SWS stages. Moreover, our results are in accordance with previous study in PD animal model reporting that ASO ( $\alpha$-synuclein over-expressing) mice did not show neither entrainment deficits to $6 \mathrm{~h}$ changes in the LD cycle or, alteration in the locomotor activity rhythm in DD (Kudo et al., 2011). Even that lead-intoxicated rats were able to adjust their locomotor activity rhythm to new LD cycle, the precision of the daily offset of activity was altered, sign of greater fragmentation in activity. All those changes described above and those reported in the studies mentioned previously postulate that lead intoxication may affect the structures and/or functions involved in the circadian timing system. Indeed, anatomical investigations suggested that in addition to other brain region (i.e., hippocampus, cerebellum, retina...), hypothalamus is a target to the neurotoxic action of lead (Wang et al., 2006; Rojas-Castaneda et al., 2011).

In mammals, SCN of the hypothalamus, the main clock pacemaker is involved in the generation and entrainment of circadian rhythms (Meijer and Rietveld, 1989; Lowrey and 


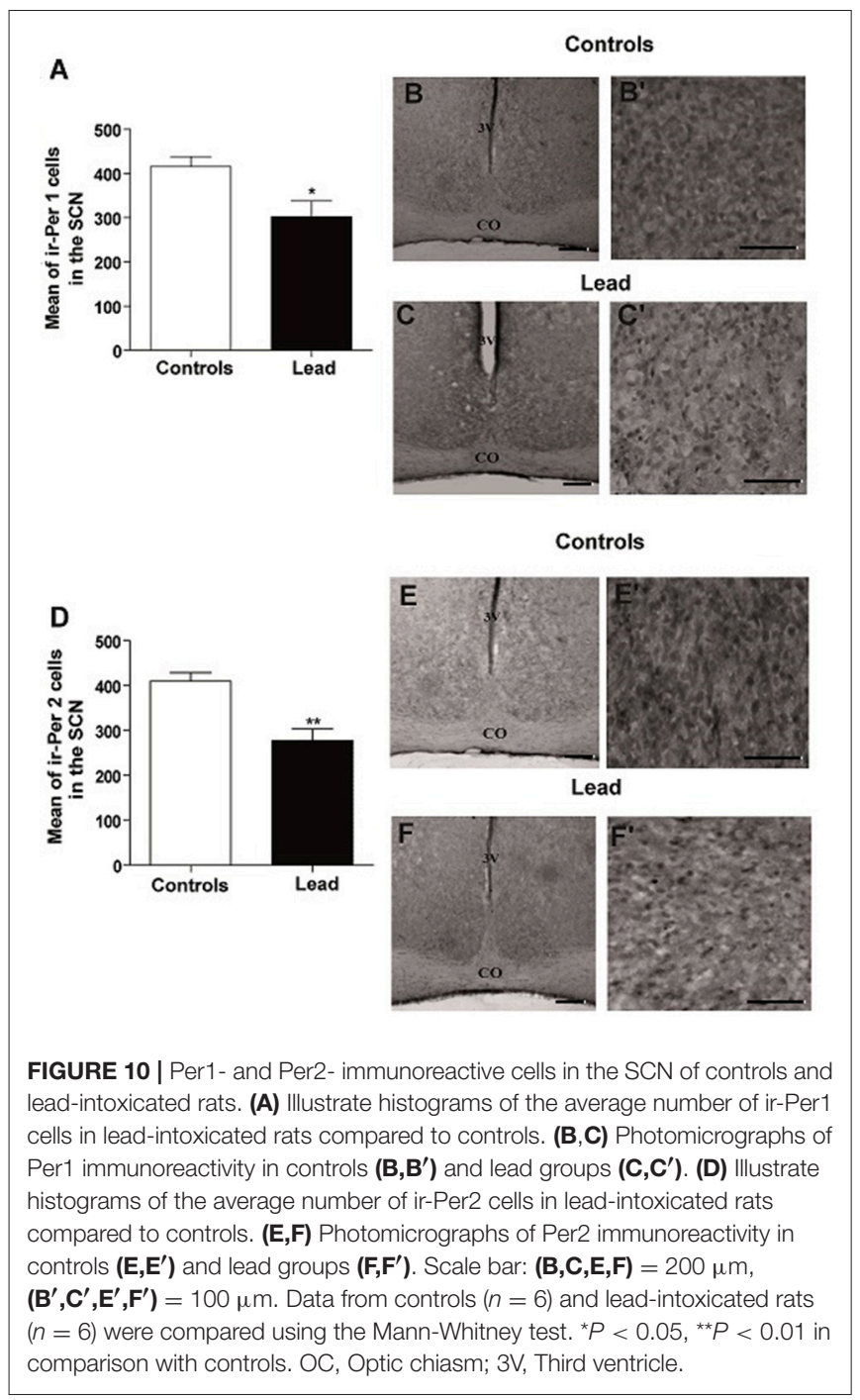

Takahashi, 2004). The circadian oscillations are generated by molecular mechanism based on feedback loops which is responsible of rhythmic transcription and translation of clock genes (Reppert and Weaver, 2001; Hastings and Herzog, 2004; Lowrey and Takahashi, 2004; Okamura, 2004). Bmal1 and Clock play a key role in feedback loop by acting as a positive regulator; CLOCK-BMAL1 heterodimer is able to induce a rhythmic transcription of other clock genes (Gekakis et al., 1998).

In the present study, we examined the clock protein expression, BMAL1, CRY1, CRY2, PER1, and PER2 in the SCN, and we found that BMAL1, PER1, and PER2 immunoreactivity were significantly declined in lead-intoxicated rats without any changes in CRY1 and CRY2 immunoreactivity in the SCN compared to controls (Figure 11). In this regard, it has been reported that in leukocytes, the expression of BMAL1 was lower in PD patients (Cai et al., 2010). Thus, the decrease in BMAL1 content in the SCN of lead-intoxicated rats could impair the molecular clock by disturbing the transcription factors of other clock genes or clock-controlled output genes. Bunger et al.

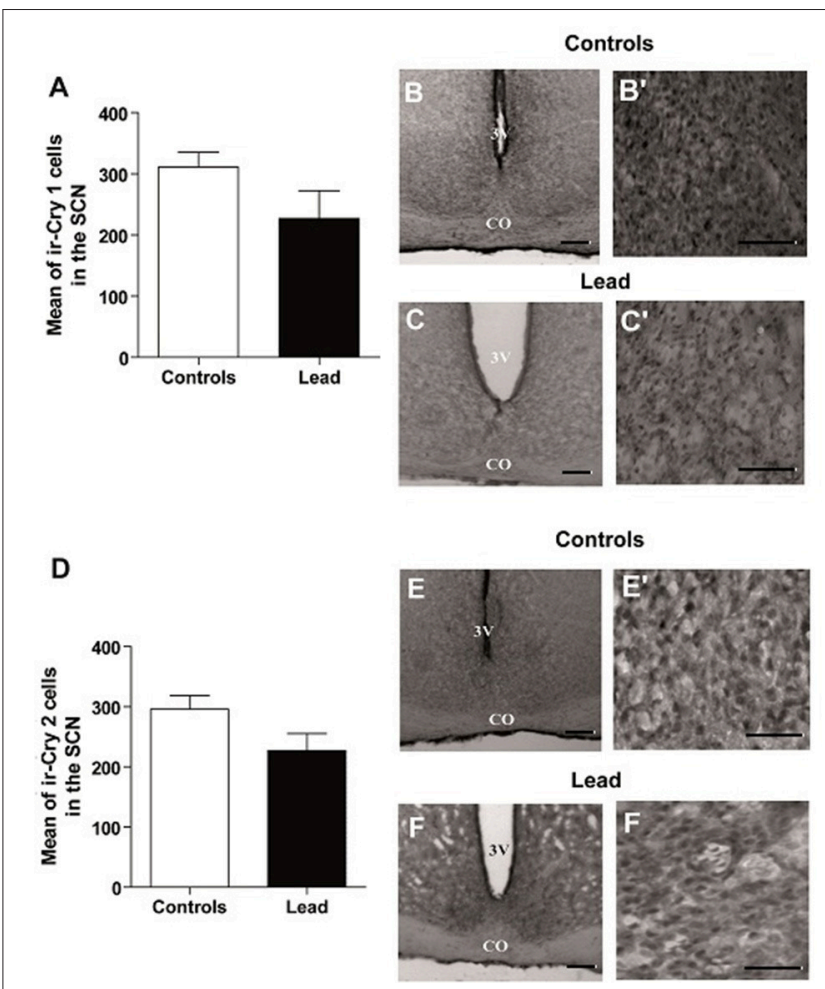

FIGURE 11 | Cry1- and Cry2- immunoreactive cells in the SCN of controls and lead-intoxicated rats. (A) Illustrate histograms of the average number of ir-Cry1 cells in lead-intoxicated rats compared to controls. $(\mathbf{B}, \mathbf{C})$

Photomicrographs of Cry1 immunoreactivity in controls (B, $\left.\mathbf{B}^{\prime}\right)$ and lead groups $\left(\mathbf{C}, \mathbf{C}^{\prime}\right)$. (D) Illustrate histograms of the average number of ir-Cry2cells in lead-intoxicated rats compared to controls. (E,F) Photomicrographs of Cry2 immunoreactivity in controls $\left(\mathbf{E}, \mathbf{E}^{\prime}\right)$ and lead groups $\left(\mathbf{F}, \mathbf{F}^{\prime}\right)$. Scale bar:

$(\mathbf{B}, \mathbf{C}, \mathbf{E}, \mathbf{F})=200 \mu \mathrm{m},\left(\mathbf{B}^{\prime}, \mathbf{C}^{\prime}, \mathbf{E}^{\prime}, \mathbf{F}^{\prime}\right)=100 \mu \mathrm{m}$. Data from controls $(n=6)$ and lead-intoxicated rats $(n=6)$ were compared using the Mann-Whitney test. OC, Optic chiasm; 3V, Third ventricle.

(2000) showed that under LD, locomotor activity rhythm is impaired and activity levels are reduced in $\mathrm{Bmal1}^{-/-}$mice which may explain the alteration of the circadian rhythm of locomotor activity in lead-intoxicated rats. Bunger et al. (2000) demonstrated also that in Bmal1 ${ }^{-/-}$mice the expression of Per1 and Per2 were very low and not rhythmic. Zheng et al. (1999) provided evidence that Perl gene is essential for the functioning of the circadian clock and that Per 2 may regulate Per1; Per2 mutation leads to a change in the expression of other genes (Per1). This mutation displays a shorter circadian period followed by a loss of circadian rhythmicity in constant darkness (Zheng et al., 1999). In DD, lead-intoxicated rats continued to express a rhythmic locomotor activity with a period of approximately $24 \mathrm{~h}$, suggesting that the decrease in PER1 and PER2 contents in the SCN may not be enough to be translated into rhythmicity loss in lead-intoxicated rats. The cryptochrome proteins, CRY1 and CRY2, act as negative regulators in the transcriptional feedback loop (van der Horst et al., 1999; Vitaterna et al., 1999), and inhibit the expression of their own genes and of period genes (Kume et al., 1999). In lead-intoxicated rats, there was no difference in 
Cry 1 and Cry 2 content in the SCN and this strength the finding that lead-intoxicated rats were rhythmic in total darkness.

In other hand, there is relevant evidence of the implication of several neurotransmitters systems in the sleep/wake regulation/modulation. In parkinsonism, sleep/wake disturbance may result in several neurotransmission failures additionally to DAergic system, i.e., NAergic neurons in the locus coeruleus (Jellinger, 1991; Zarow et al., 2003; Fulceri et al., 2007), and serotonergic neurons in the raphe (Kish, 2003; Kish et al., 2008). Lead is also known to affect neurotransmitter systems, including NA and DA systems (Silbergeld, 1983; Sabbar et al., 2012). We did not measure concentrations of NA or DA following lead intoxication in this study, but we recently find a decrease in striatal DA concentration (unpublished data) and changes in cortical NA concentration in lead-intoxicated rats (same dose and same route of administration; 8). Since NA containing fibers and terminals were demonstrated in the SCN (Cagampang et al., 1994; Jacomy and Bosler, 1995; Vacher et al., 2003), the role of either NA or DA cannot be excluded to explain the circadian rhythm alterations during lead intoxication.

NA might modulate SCN circadian rhythms by regulating the expression of arginine-vasopressin and vasoactive intestinal peptides, two neuropeptides involved in the control of circadian rhythms as previously reported by Vacher et al. (2003). This neurotransmitter might also affect clock genes expression as reported in the astroglial cells of the SCN (Morioka et al., 2010). Furthermore, DA has been shown to modulate the expression of the clock genes (Imbesi et al., 2009) and regulate the BMAL1/CLOCK heterodimer activity (Yujnovsky et al., 2006). A decrease of DA level in the striatum in lead-intoxicated rats (unpublished data) may suggest that this heavy metal may impair the modulatory role that DA exerts and could explain partially the changes in clock protein expression our lead-intoxicated rats. This hypothesis has however to be confirmed by additional experiences.

\section{REFERENCES}

Almirall, H., Bautista, V., Sanchez-Bahillo, A., and Trinidad-Herrero, M. (2001). Ultradian and circadian body temperature and activity rhythms in chronic MPTP treated monkeys. Neurophysiol. Clin. 31, 161-170. doi: 10.1016/S0987-7 053(01)00256-8

Alzahrani, H., and Venneri, A. (2015). Cognitive and neuroanatomical correlates of neuropsychiatric symptoms in Parkinson's disease: a systematic review. J. Neurol. Sci. 356, 32-44. doi: 10.1016/j.jns.2015.06.037

Arnulf, I., Konofal, E., Merino-Andreu, M., Houeto, J. L., Mesnage, V., Welter, M. L., et al. (2002). Parkinson's disease and sleepiness: an integral part of PD. Neurology 58, 1019-1024. doi: 10.1212/WNL.58.7.1019

Barone, P., Antonini, A., Colosimo, C., Marconi, R., Morgante, L., Avarello, T. P., et al. (2009). The PRIAMO study: a multicenter assessment of nonmotor symptoms and their impact on quality of life in Parkinson's disease. Mov. Disord. 24, 1641-1649. doi: 10.1002/mds.22643

Barraud, Q., Lambrecq, V., Forni, C., McGuire, S., Hill, M., Bioulac, B., et al. (2009). Sleep disorders in Parkinson's disease: the contribution of the MPTP non-human primate model. Exp. Neurol. 219, 574-582. doi: 10.1016/j.expneurol.2009.07.019

Ben, V., and Bruguerolle, B. (2000). Effects of bilateral striatal 6-OHDA lesions on circadian rhythms in the rat: a radiotelemetric study. Life Sci. 67, 1549-1558. doi: 10.1016/S0024-3205(00)00751-7
In conclusion, we have confirmed that lead intoxication induced motor disabilities similar to those reported in animal models of PD. Moreover, we have shown that several $24 \mathrm{~h}$ locomotor activity parameters were altered, associated with a decrease in bmal1, per1, and per 2 contents in the SCN. Tough, $24 \mathrm{~h}$ rest/activity disturbances, have never been extensively explored following lead intoxication, it may be interesting to investigate the mechanism(s) by which lead disrupt circadian rhythmicity, thereby providing evidence that might link lead neurotoxicity to induce Parkinsonism.

\section{AUTHOR CONTRIBUTIONS}

NL designed the experimental protocol. MS collected, analyzed the data, wrote and edited the manuscript. OD assisted with data analysis. NL and $\mathrm{AB}$ edited and approved the final draft of the manuscript. All authors read and approved the final manuscript.

\section{FUNDING}

This research was funded by the "Université Mohammed V de Rabat," Rhône-Alpes CMIRA research Grant and CNRS-CNRST Convention Adivmar 22614.

\section{ACKNOWLEDGMENTS}

We are very grateful to Dr. Cooper Howard for sharing his expertise and helping us to set up the locomotor activity acquisition system CAMS (Circadian Activity Monitoring System). We thank Dr. Elisabeth Maywood for her generous gift of clock protein antibodies. Dr. N. Bouhaddou and our Ph.D. students Ms. M. S. Klouche and Ms. D. Salhi are thanked for their assistance during perfusion, immunohistochemistry, and animal care assistance.

Bouabid, S., Delaville, C., De Deurwaerdere, P., Lakhdar-Ghazal, N., and Benazzouz, A. (2014). Manganese-induced atypical parkinsonism is associated with altered basal ganglia activity and changes in tissue levels of monoamines in the rat. PLoS ONE 9:e98952. doi: 10.1371/journal.pone.0098952

Boulamery, A., Simon, N., Vidal, J., and Bruguerolle, B. (2010). Effects of L-Dopa on circadian rhythms of 6-OHDA striatal lesioned rats: a radiotelemetric study. Chronobiol. Int. 27, 251-264. doi: 10.3109/07420521003664213

Breen, D. P., Vuono, R., Nawarathna, U., Fisher, K., Shneerson, J. M., Reddy, A. B., et al. (2014). Sleep and circadian rhythm regulation in early Parkinson disease. JAMA Neurol. 71, 589-595. doi: 10.1001/jamaneurol.2014.65

Bunger, M. K., Wilsbacher, L. D., Moran, S. M., Clendenin, C., Radcliffe, L. A., Hogenesch, J. B., et al. (2000). Mop3 is an essential component of the master circadian pacemaker in mammals. Cell 103, 1009-1017. doi: 10.1016/s0092-8674(00)00205-1

Cagampang, F. R., Okamura, H., and Inouye, S. (1994). Circadian rhythms of norepinephrine in the rat suprachiasmatic nucleus. Neurosci. Lett. 173, 185-188. doi: 10.1016/0304-3940(94)90179-1

Cai, Y., Liu, S., Sothern, R. B., Xu, S., and Chan, P. (2010). Expression of clock genes Per1 and Bmal1 in total leukocytes in health and Parkinson's disease. Eur. J. Neurol. 17, 550-554. doi: 10.1111/j.1468-1331.2009.02848.x

Chaudhuri, K. R., Healy, D. G., and Schapira, A. H. (2006). Non-motor symptoms of Parkinson's disease: diagnosis and management. Lancet Neurol. 5, 235-245. doi: 10.1016/S1474-4422(06)70373-8 
Collins, M. F., Hrdina, P. D., Whittle, E., and Singhal, R. L. (1984). The effects of low-level lead exposure in developing rats: changes in circadian locomotor activity and hippocampal noradrenaline turnover. Can. J. Physiol. Pharmacol. 62, 430-435.

Coon, S., Stark, A., Peterson, E., Gloi, A., Kortsha, G., Pounds, J., et al. (2006). Whole-body lifetime occupational lead exposure and risk of Parkinson's disease. Environ. Health Perspect. 114, 1872-1876. doi: 10.1289/ehp.9102

Delaville, C., Chetrit, J., Abdallah, K., Morin, S., Cardoit, L., De Deurwaerdere, P., et al. (2012). Emerging dysfunctions consequent to combined monoaminergic depletions in Parkinsonism. Neurobiol. Dis. 45, 763-773. doi: $10.1016 /$ j.nbd.2011.10.023

Ehringer, H., and Hornykiewicz, O. (1960). [Distribution of noradrenaline and dopamine (3-hydroxytyramine) in the human brain and their behavior in diseases of the extrapyramidal system]. Klin. Wochenschr. 38:1236-1239.

El Moussaouiti, R., Bouhaddou, N., Sabbar, M., Cooper, H. M., and Lakhdar-Ghazal, N. (2010). Phase and period responses of the jerboa Jaculus orientalis to short light pulses. Chronobiol. Int. 27, 1348-1364. doi: 10.3109/07420528.2010.504315

Faggiani, E., Delaville, C., and Benazzouz, A. (2015). The combined depletion of monoamines alters the effectiveness of subthalamic deep brain stimulation. Neurobiol. Dis. 82, 342-348. doi: 10.1016/j.nbd.2015.07.010

Ferreira, J. J., Desboeuf, K., Galitzky, M., Thalamas, C., Brefel-Courbon, C., Fabre, N., et al. (2006). Sleep disruption, daytime somnolence and 'sleep attacks' in Parkinson's disease: a clinical survey in PD patients and age-matched healthy volunteers. Eur. J. Neurol. 13, 209-214. doi: 10.1111/j.1468-1331.2006.01262.x

Fifel, K., Piggins, H., and Deboer, T. (2016). Modeling sleep alterations in Parkinson's disease: how close are we to valid translational animal models? Sleep Med. Rev. 25, 95-111. doi: 10.1016/j.smrv.2015.02.005

Fulceri, F., Biagioni, F., Ferrucci, M., Lazzeri, G., Bartalucci, A., Galli, V., et al. (2007). Abnormal involuntary movements (AIMs) following pulsatile dopaminergic stimulation: severe deterioration and morphological correlates following the loss of locus coeruleus neurons. Brain Res. 1135, 219-229. doi: 10.1016/j.brainres.2006.12.030

Gekakis, N., Staknis, D., Nguyen, H. B., Davis, F. C., Wilsbacher, L. D., King, D. P., et al. (1998). Role of the CLOCK protein in the mammalian circadian mechanism. Science 280, 1564-1569.

Gill, K. D., Gupta, V., and Sandhir, R. (2003). $\mathrm{Ca}^{2+/}$ calmodulin-mediated neurotransmitter release and neurobehavioural deficits following lead exposure. Cell Biochem. Funct. 21, 345-353. doi: 10.1002/cbf.1030

Gorell, J. M., Johnson, C. C., Rybicki, B. A., Peterson, E. L., Kortsha, G. X., Brown, G. G., et al. (1997). Occupational exposures to metals as risk factors for Parkinson's disease. Neurology. 48, 650-658. doi: 10.1212/WNL.48.3.650

Gorell, J. M., Johnson, C. C., Rybicki, B. A., Peterson, E. L., Kortsha, G. X., Brown, G. G., et al. (1999a). Occupational exposure to manganese, copper, lead, iron, mercury and zinc and the risk of Parkinson's disease. Neurotoxicology 20, 239-247.

Gorell, J. M., Rybicki, B. A., Cole Johnson, C., and Peterson, E. L. (1999b). Occupational metal exposures and the risk of Parkinson's disease. Neuroepidemiology 18, 303-308. doi: 10.1159/000026225

Gunn, D. G., Naismith, S. L., and Lewis, S. J. (2010). Sleep disturbances in Parkinson disease and their potential role in heterogeneity. J. Geriatr. Psychiatry Neurol. 23, 131-137. doi: 10.1177/0891988709358591

Hastings, M. H., and Herzog, E. D. (2004). Clock genes, oscillators, and cellular networks in the suprachiasmatic nuclei. J. Biol. Rhythms. 19, 400-413. doi: 10.1177/0748730404268786

Imbesi, M., Yildiz, S., Dirim Arslan, A., Sharma, R., Manev, H., and Uz, T. (2009). Dopamine receptor-mediated regulation of neuronal "clock" gene expression. Neuroscience 158, 537-544. doi: 10.1016/j.neuroscience.2008.10.044

Ishihara, L., and Brayne, C. (2006). A systematic review of depression and mental illness preceding Parkinson's disease. Acta Neurol. Scand. 113, 211-220. doi: 10.1111/j.1600-0404.2006.00579.x

Jacomy, H., and Bosler, O. (1995). Catecholaminergic innervation of the suprachiasmatic nucleus in the adult rat: ultrastructural relationships with neurons containing vasoactive intestinal peptide or vasopressin. Cell Tissue Res. 280, 87-96. doi: 10.1007/BF00304514

Jason, K. M., and Kellogg, C. K. (1981). Neonatal lead exposure: effects on development of behavior and striatal dopamine neurons. Pharmacol. Biochem. Behav. 15, 641-649. doi: 10.1016/0091-3057(81)90223-9
Jellinger, K. A. (1991). Pathology of Parkinson's disease. Changes other than the nigrostriatal pathway. Mol. Chem. Neuropathol. 14, 153-197.

Kala, S. V., and Jadhav, A. L. (1995). Low level lead exposure decreases in vivo release of dopamine in the rat nucleus accumbens: a microdialysis study. J. Neurochem. 65, 1631-1635. doi: 10.1046/j.1471-4159.1995.650 41631.x

Kish, S. J. (2003). Biochemistry of Parkinson's disease: is a brain serotonergic deficiency a characteristic of idiopathic Parkinson's disease? Adv. Neurol. 91, 39-49.

Kish, S. J., Tong, J., Hornykiewicz, O., Rajput, A., Chang, L. J., Guttman, M., et al. (2008). Preferential loss of serotonin markers in caudate versus putamen in Parkinson's disease. Brain 131(Pt 1), 120-131. doi: 10.1093/brain/awm239

Kudo, T., Loh, D. H., Truong, D., Wu, Y., and Colwell, C. S. (2011). Circadian dysfunction in a mouse model of Parkinson's disease. Exp. Neurol. 232, 66-75. doi: 10.1016/j.expneurol.2011.08.003

Kumar, M. V., and Desiraju, T. (1992). EEG spectral power reduction and learning disability in rats exposed to lead through postnatal developing age. Indian J. Physiol. Pharmacol. 36, 15-20.

Kume, K., Zylka, M. J., Sriram, S., Shearman, L. P., Weaver, D. R., Jin, X., et al. (1999). mCRY1 and mCRY2 are essential components of the negative limb of the circadian clock feedback loop. Cell 98, 193-205.

Lahouaoui, H., Coutanson, C., Cooper, H. M., Bennis, M., and DkhissiBenyahya, O. (2014). Clock genes and behavioral responses to light are altered in a mouse model of diabetic retinopathy. PLoS ONE 9:e101584. doi: 10.1371/journal.pone.0101584

Langmesser, S., Franken, P., Feil, S., Emmenegger, Y., Albrecht, U., and Feil, R. (2009). cGMP-dependent protein kinase type I is implicated in the regulation of the timing and quality of sleep and wakefulness. PLOS ONE 4:e4238. doi: 10.1371/journal.pone.0004238

Lima, M. M., Andersen, M. L., Reksidler, A. B., Vital, M. A., and Tufik, S. (2007). The role of the substantia nigra pars compacta in regulating sleep patterns in rats. PLoS ONE 2:e513. doi: 10.1371/journal.pone.0000513

Lowrey, P. L., and Takahashi, J. S. (2004). Mammalian circadian biology: elucidating genome-wide levels of temporal organization. Annu. Rev. Genomics Hum. Genet. 5, 407-441. doi: 10.1146/annurev.genom.5.061903.175925

Meijer, J. H., and Rietveld, W. J. (1989). Neurophysiology of the suprachiasmatic circadian pacemaker in rodents. Physiol. Rev. 69, 671-707.

Menza, M., Dobkin, R. D., Marin, H., and Bienfait, K. (2010). Sleep disturbances in Parkinson's disease. Mov. Disord. 25(Suppl. 1), S117-S122. doi: $10.1002 / \mathrm{mds} .22788$

Morioka, N., Sugimoto, T., Tokuhara, M., Dohi, T., and Nakata, Y. (2010). Noradrenaline induces clock gene Per1 mRNA expression in C6 glioma cells through $\beta_{2}$-adrenergic receptor coupled with protein kinase A cAMP response element binding protein (PKA-CREB) and Src-tyrosine kinase-glycogen synthase kinase-3 $\beta$ (Src-GSK-3 $\beta$ ). J. Pharmacol. Sci. 113 234-245. doi: 10.1254/jphs.10031fp

NourEddine, D., Miloud, S., and Abdelkader, A. (2005). Effect of lead exposure on dopaminergic transmission in the rat brain. Toxicology 207, 363-368. doi: $10.1016 /$ j.tox.2004.10.016

Okamura, H. (2004). Clock genes in cell clocks: roles, actions, and mysteries. J. Biol. Rhythms 19, 388-399. doi: 10.1177/0748730404269169

Overmann, S. R. (1977). Behavioral effects of asymptomatic lead exposure during neonatal development in rats. Toxicol. Appl. Pharmacol. 41, 459-471.

Pace-Schott, E. F., and Hobson, J. A. (2002). The neurobiology of sleep: genetics, cellular physiology and subcortical networks. Nat. Rev. Neurosci. 3, 591-605. doi: $10.1038 / \mathrm{nrn} 895$

Refinetti, R. (2006). Variability of diurnality in laboratory rodents. J. Com. Physiol. A Neuroethol. Sens. Neural Behav. Physiol. 192, 701-714. doi: 10.1007/s00359-006-0093-X

Reiter, L. W., Anderson, G. E., Laskey, J. W., and Cahill, D. F. (1975). Developmental and behavioral changes in the rat during chronic exposure to lead. Environ. Health Perspect. 12, 119-123. doi: 10.1289/ehp.7512119

Reppert, S. M., and Weaver, D. R. (2001). Molecular analysis of mammalian circadian rhythms. Annu. Rev. Physiol. 63, 647-676. doi: 10.1146/annurev.physiol.63.1.647

Rodrigues, A. L., Rocha, J. B., Mello, C. F., and Souza, D. O. (1996). Effect of perinatal lead exposure on rat behaviour in open-field and two-way avoidance tasks. Pharmacol. Toxicol. 79, 150-156. 
Rojas-Castaneda, J. C., Vigueras-Villasenor, R. M., Rojas, P., Chavez-Saldana, M., Gutierrez-Perez, O., Montes, S., et al. (2011). Alterations induced by chronic lead exposure on the cells of circadian pacemaker of developing rats. Int. J. Exp. Pathol. 92, 243-250. doi: 10.1111/j.1365-2613.2011.00761.x

Sabbar, M., Delaville, C., De Deurwaerdere, P., Benazzouz, A., and LakhdarGhazal, N. (2012). Lead intoxication induces noradrenaline depletion, motor nonmotor disabilities, and changes in the firing pattern of subthalamic nucleus neurons. Neuroscience 210, 375-383. doi: 10.1016/j.neuroscience.2012.02.026

Sansar, W., Ahboucha, S., and Gamrani, H. (2011). Chronic lead intoxication affects glial and neural systems and induces hypoactivity in adult rat. Acta Histochem. 113, 601-607. doi: 10.1016/j.acthis.2010.06.005

Shafiq ur Rehman. (1999). Circadian rhythm of stereotyped complex behaviours in rats in environmental lead exposure. Prog. Neuropsychopharmacol. Biol. Psychiatry. 23, 149-159.

Shafiq ur Rehman, Khushnood ur Rehman, Kabir ud, D, and Chandra, O. (1986). Differential effects of chronic lead intoxication on circadian rhythm of ambulatory activity and on regional brain norepinephrine levels in rats. Bull. Environ. Contam. Toxicol. 36, 81-91. doi: 10.1007/BF01623478

Shafiq-ur-Rehman, S. (1991). Effects of lead on the behavioral complex stereotypes and regional brain dopamine levels in rats. Arch. Environ. Contam. Toxicol. 20, 527-530. doi: 10.1007/BF01065844

Shulman, L. M., Taback, R. L., Bean, J., and Weiner, W. J. (2001). Comorbidity of the nonmotor symptoms of Parkinson's disease. Mov. Disord. 16, 507-510. doi: $10.1002 / \mathrm{mds} .1099$

Silbergeld, E. K. (1983). Localization of metals: issues of importance to neurotoxicology of lead. Neurotoxicology 4, 193-200.

Smith, A. K., Togeiro, S. M., and Tufik, S., Roizenblatt, S. (2009). Disturbed sleep and musculoskeletal pain in the bed partner of patients with obstructive sleep apnea. Sleep Med. 10, 904-912. doi: 10.1016/j.sleep.2008.08.013

Smith, K. S., and Morrell, J. I., (2007). Comparison of infant and adult rats in exploratory activity, diurnal patterns, and responses to novel and anxiety-provoking environments. Behav. Neurosci. 121, 449-461. doi: 10.1037/0735-7044.121.3.449

Stephan, F. K., and Zucker, I. (1972). Circadian rhythms in drinking behavior and locomotor activity of rats are eliminated by hypothalamic lesions. Proc. Natl. Acad. Sci. U.S.A. 69, 1583-1586. doi: 10.1073/pnas.69.6.1583

Stevens, S., Cormella, C. L., and Stepanski, E. J. (2004). Daytime sleepiness and alertness in patients with Parkinson disease. Sleep 27, 967-972. doi: 10.1093/sleep/27.5.967

Tavakoli-Nezhad, M., Barron, A. J., and Pitts, D. K. (2001). Postnatal inorganic lead exposure decreases the number of spontaneously active midbrain dopamine neurons in the rat. Neurotoxicology 22, 259-269. doi: 10.1016/S0161-813X(01)00010-9

Thorpy, M. J., and Adler, C. H. (2005). Parkinson's disease and sleep. Neurol. Clin. 23, 1187-1208. doi: 10.1016/j.ncl.2005.05.001

Vacher, C. M., Fretier, P., Creminon, C., Seif, I., De Maeyer, E., Calas, A., et al. (2003). Monoaminergic control of vasopressin and VIP expression in the mouse suprachiasmatic nucleus. J. Neurosci. Res. 71, 791-801. doi: 10.1002/jnr.10529

van der Horst, G. T., Muijtjens, M., Kobayashi, K., Takano, R., Kanno, S., Takao, M., et al. (1999). Mammalian Cry1 and Cry2 are essential for maintenance of circadian rhythms. Nature 398, 627-630.

van Hilten, B., Hoff, J. I., Middelkoop, H. A., van der Velde, E. A., Kerkhof, G. A., Wauquier, A., et al. (1994). Sleep disruption in Parkinson's disease. assessment by continuous activity monitoring. Arch. Neurol. 51, 922-928.

van Hilten, J. J., Weggeman, M., van der Velde, E. A., Kerkhof, G. A., van Dijk, J. G., and Roos, R. A. (1993). Sleep, excessive daytime sleepiness and fatigue in Parkinson's disease. J. Neural Trans. Park. Dis. Dement. Sect. 5, 235-244.

Vitaterna, M. H., Selby, C. P., Todo, T., Niwa, H., Thompson, C., Fruechte, E. M., et al. (1999). Differential regulation of mammalian period genes and circadian rhythmicity by cryptochromes 1 and 2. Proc. Natl. Acad. Sci. U.S.A. 96, 12114-12119.

Wang, J., Wu, J., and Zhang, Z. (2006). Oxidative stress in mouse brain exposed to lead. Ann. Occup. Hyg. 50, 405-409. doi: 10.1093/annhyg/mei079

Weisskopf, M. G., Weuve, J., Nie, H., Saint-Hilaire, M. H., Sudarsky, L., Simon, D. K., et al. (2010). Association of cumulative lead exposure with Parkinson's disease. Environ. Health Perspect. 118, 1609-1613. doi: 10.1289/ehp.1002339

Willison, L. D., Kudo, T., Loh, D. H., Kuljis, D., and Colwell, C. S. (2013). Circadian dysfunction may be a key component of the non-motor symptoms of Parkinson's disease: insights from a transgenic mouse model. Exp. Neurol. 243, 57-66. doi: 10.1016/j.expneurol.2013.01.014

Yujnovsky, I., Hirayama, J., Doi, M., Borrelli, E., and Sassone-Corsi, P. (2006). Signaling mediated by the dopamine D2 receptor potentiates circadian regulation by CLOCK:BMAL1. Proc. Natl. Acad. Sci. U.S.A. 103, 6386-6391. doi: 10.1073/pnas.0510691103

Zarow, C., Lyness, S. A., Mortimer, J. A., and Chui, H. C. (2003). Neuronal loss is greater in the locus coeruleus than nucleus basalis and substantia nigra in Alzheimer and Parkinson diseases. Arch. Neurol. 60, 337-341. doi: 10.1001/archneur.60.3.337

Zheng, B., Larkin, D. W., Albrecht, U., Sun, Z. S., Sage, M., Eichele, G., et al. (1999). The mPer2 gene encodes a functional component of the mammalian circadian clock. Nature 400, 169-173.

Conflict of Interest Statement: The authors declare that the research was conducted in the absence of any commercial or financial relationships that could be construed as a potential conflict of interest.

Copyright (C) 2017 Sabbar, Dkhissi-Benyahya, Benazzouz and Lakhdar-Ghazal. This is an open-access article distributed under the terms of the Creative Commons Attribution License (CC BY). The use, distribution or reproduction in other forums is permitted, provided the original author(s) or licensor are credited and that the original publication in this journal is cited, in accordance with accepted academic practice. No use, distribution or reproduction is permitted which does not comply with these terms. 